This article has been published as Körber, M., Gold, C., Lechner, D., \& Bengler, K. (2016). The influence of age on the take-over of vehicle control in highly automated driving. Transportation Research Part F: Traffic Psychology and Behaviour, 39, 19-32. doi:10.1016/j.trf.2016.03.002

\title{
The Influence Of Age On The Take-Over Of Vehicle Control In Highly Automated Driving
}

\author{
Moritz Körber \\ Institute of Ergonomics, \\ Technische Universität \\ München \\ Boltzmannstraße 15, \\ 85747 Garching \\ Tel: +49 8928915376 \\ koerber@lfe.mw.tum.de
}

\author{
Christian Gold \\ Institute of Ergonomics, \\ Technische Universität \\ München \\ Boltzmannstraße 15, \\ 85747 Garching \\ Tel: +49 8928915401 \\ gold@lfe.mw.tum.de
}

\author{
David Lechner \\ Institute of Ergonomics, \\ Technische Universität \\ München \\ Boltzmannstraße 15, \\ 85747 Garching \\ lechnerd@lfe.mw.tum.de
}

\author{
Klaus Bengler \\ Institute of Ergonomics, \\ Technische Universität \\ München \\ Boltzmannstraße 15, \\ 85747 Garching \\ Tel: +4989 28915400 \\ bengler@lfe.mw.tum.de
}

Correspondence concerning this article should be addressed to Moritz Körber, Institute of Ergonomics, Technische Universität München, Boltzmannstraße 15, D - 85747 Garching, Tel: +49 89289 15376, Email: koerber@Ife.mw.tum.de

\begin{abstract}
The growing proportion of older drivers in the population plays an increasingly relevant role in road traffic that is currently awaiting the introduction of automated vehicles. In this study, it was investigated how older drivers ( $\geq 60$ years) compared to younger drivers ( $\leq 28$ years) perform in a critical traffic event when driving highly automated. Conditions of the take-over situation were manipulated by adding a verbal non-driving task ( 20 questions task) and by variation of traffic density. Two age groups consisting of 36 younger and 36 older drivers drove either with or without a non-driving task on a six-lane highway. They encountered three situations with either no, medium or high traffic density where they had to regain vehicle control and evade an obstacle on the road. Older drivers reacted as fast as younger drivers, however, they differed in their modus operandi as they braked more often and more strongly and maintained a higher time-to-collision (TTC). Deterioration of take-over time and quality caused by increased traffic density and engagement in a non-driving task was on the same level for both age groups. Independent of the traffic density, there was a learning effect for both younger and older drivers in a way that the take-over time decreased, minimum TTC increased and maximum lateral acceleration decreased between the first and the last situation of the experiment. Results highlight that older drivers are able to solve critical traffic events as well as younger drivers, yet their modus operandi differs. Nevertheless, both age groups adapt to the experience of take-over situations in the same way.
\end{abstract}

Keywords: automated driving, age, human-automation-interaction, traffic density, non-driving task.

\section{Introduction}

Nowadays, industrialized nations are witnessing a major change in demographics since the proportion of older people in the population is steadily growing. According to Cauley (2012), the proportion of people in the global population older than 65 years will double from 7 to $14 \%$ by 2040 . Accompanied by that is an increased number of elderly drivers in road traffic. It is controversially discussed whether older drivers have increased involvement in accidents. Frailty bias (overrepresentation in registered accidents because of their increasing physical frailty) and low mileage bias (driver with low yearly driving distances have a higher risk per kilometer) show that a simple measurement by crash rate based on distance driven might result in a skewed image (Langford, Methorst, \& Hakamies-Blomqvist, 2006). In addition, older drivers differ from younger drivers in the type of crashes (Cicchino \& McCartt, 2015; 
This article has been published as Körber, M., Gold, C., Lechner, D., \& Bengler, K. (2016). The influence of age on the take-over of vehicle control in highly automated driving. Transportation Research Part F: Traffic Psychology and Behaviour, 39, 19-32. doi:10.1016/j.trf.2016.03.002

Dotzauer, Waard, Caljouw, Pöhler, \& Brouwer, 2015) and show compensatory driving behavior, i.e. driving in conditions and at demands that are appropriate for their abilities (Andrews \& Westerman, 2012). Therefore, accounting for multiple factors (how much is driven, in what situation, where, when and how) is important for estimating elderly drivers' crash risk (Blanchard, Myers, \& Porter, 2010).

Aging is accompanied by a decline in cognitive functions (Salthouse, 2009) and since driving is a complex task, such impairments may also be relevant for safe road behavior. Anstey and colleagues (Anstey, Wood, Lord, \& Walker, 2005) give an overview of age-related changes relevant to driving and show that the relationship between the decline in performance in cognitive tests and reported crash involvement varies. Impairments and decline relevant to driving include executive functions (Bryan \& Luszcz, 2000), impaired vision (Haegerstrom-Portnoy, Schneck, \& Brabyn, 1999), perception of hazards (Horswill et al., 2008), reaction times (Der \& Deary, 2006), and information processing speed (Salthouse, 1991; Verhaeghen \& Salthouse, 1997). Additionally, their visual search is altered (Maltz \& Shinar, 1999), older drivers make more mistakes in estimating the speed of other vehicles (Scialfa, Guzy, Leibowitz, Garvey, \& Tyrrell, 1991), they take longer to switch tasks (Kray \& Lindenberger, 2000), and solve novel problems worse (Baltes, Staudinger, \& Lindenberger, 1999). However, although every aging individual is affected by this decline, its speed and intensity vary strongly between them (Hultsch, MacDonald, \& Dixon, 2002) and this variability, in addition, increases with age (Morse, 1993). Hertzog et al. (2008) describe the decline as a "zone of possible functioning" (p. 1) whose borders are set by person-specific endowments and age-related constraints. According to them, an individual's position in this zone is dependent on the individual engagement in gainful intellectual, physical, and social activities. Therefore, given the right conditions, proper cognitive functioning can be maintained even at an higher age. Furthermore, performance in naturalistic common tasks does not only depend on elementary general cognitive abilities but is also influenced by specific knowledge and expertise (Masunaga \& Horn, 2001). Even performance in cognitive tasks, laboratory or naturalistic, is partially based on acquired relevant information structures (Hertzog, 2008), which limits the external validity of laboratory tests. Development of cognitive performance is thereby not only a function of age, but also of compensatory adaptations, experience-related changes, and acquisition of expertise. From this perspective, aging does not necessarily lead to a deterioration in driving performance for everyone, but depends on the situation and individual lifestyle.

While the impact of this decline on road safety has already been studied in manual driving (e.g. Devlin, McGillivray, Charlton, Lowndes, \& Etienne, 2012; Horberry, Anderson, Regan, Triggs, \& Brown, 2006), the planned introduction of vehicle automation to mass-production vehicles creates the need to investigate older drivers' interaction with vehicle automation. This introduction initiates a shift in vehicle control since the ability to let longitudinal control as well as lateral control be carried out by an automation is now provided (Gold \& Bengler, 2014). This shift also influences the driver's tasks and their demands: In highly automated driving (Gasser, 2012; Level 3 in NHTSA, 2013), the driver is not actively taking part in the controller-vehicle loop and, therefore, it is now possible for him to engage in nondriving-related activities (e.g. reading e-mails). If the system detects a system limit, it then requests the driver to take over vehicle control in a certain amount of time. Thus, the driver now has to react quickly, must be able to switch from secondary tasks to manual driving and has to gather information about the environment as well as the reason for the takeover request (TOR) and has to choose the best reaction. If vehicle automation is to be introduced into road traffic, safe use for every potential user has to be ensured (Körber \& Bengler, 2014). Since reaction times (Der \& Deary, 2006), processing speed (Salthouse, 1991), task switching (Kray \& Lindenberger, 2000) and hazard perception response time (Horswill et al., 2008) decline with age, it seems reasonable that older drivers could take longer to regain vehicle control in case of a TOR. Petermann-Stock and colleagues (Petermann-Stock, Hackenberg, Muhr, \& Mergl, 2013) investigated the influence of age on take-over time with a younger driver 
This article has been published as Körber, M., Gold, C., Lechner, D., \& Bengler, K. (2016). The influence of age on the take-over of vehicle control in highly automated driving. Transportation Research Part F: Traffic Psychology and Behaviour, 39, 19-32. doi:10.1016/j.trf.2016.03.002

(25-35 years) and an older driver (50-70 years) group. They found a difference of up to $1200 \mathrm{~ms}$ (depending on the workload condition) between the means in take-over time of the two age groups, although this difference was not significant. A reason for this result could lie in the study design: the participants drove at rather low speed $(35 \mathrm{~km} / \mathrm{h})$ and no immediate reaction by the participants was necessary. It is imaginable that the participants did not react as fast as possible and took their time to comfortably take over, which could have ruled out any age-related differences in reaction times. Thus, more research about take-over time of older drivers and, given the mentioned performance variations of older drivers dependent on the situation, relevant situational influences is needed. In this study, we, therefore, investigate the influence of age on take-over time in highly automated driving in varying conditions.

\section{Situation Complexity as Intensifier of Age Effects}

Depending on the time and location of the drive, the number of other road users might vary. Other road users increase the complexity of a situation and the number of objects that have to be monitored or taken into account in the decision-making process. Accordingly, Baldwin and Coyne (2003) found significant processing decrements, indicated by higher response times and lower accuracy, in a detection task as a function of increased traffic density, although subjective ratings and EEG results did not differ significantly between the conditions. Strayer, Drews and Johnson (2003) report an exacerbation of the difference between single- and dual-task conditions by traffic density: participants were more often involved in a traffic accident while talking on a cell phone when the traffic density was high. Törnros and Bolling (2006) found performance in a peripheral detection task (PDT) to be remarkably poor in a complex urban environment, even when there was no engagement in a secondary task. Drivers' reduction of speed in this environment was seen as a compensatory measure caused by higher task demands. In a driving simulator study, Trick and colleagues (Trick, Toxopeus, \& Wilson, 2010) showed that high traffic density leads to longer hazard reaction times and a higher standard deviation of lane position. Radlmayr et al. (Radlmayr, Gold, Lorenz, Farid, \& Bengler, 2014) investigated the effect of high traffic density during a take-over situation in highly automated driving and found a large increase in take-over time when other road users were present. However, generalization of their results to the general driving population is difficult, because their mean sample age was rather low. The increase in take-over time could even be larger for elderly drivers since age-related differences in performance have been found to be exacerbated by an increase in task complexity (Salthouse, 1987, 1988). Accordingly, Horberry and colleagues (Horberry et al., 2006) found that older drivers drive slower in highly complex environments to allow themselves an increased margin of error, i.e. to compensate for the high task demand (Fuller, 2005). Cantin and colleagues (Cantin, Lavallière, Simoneau, \& Teasdale, 2009) also reported a disproportionate increase in reaction times for older participants in the most complex driving context, although others could not replicate this finding (Stinchcombe \& Gagnon, 2013), which highlights the high variability and context dependency of age effects and cognitive decline. To elaborate the possible interaction between age and situational complexity further, we manipulated situational complexity in this study by variation of traffic density. Compared to no traffic, a high traffic density incorporates more vehicles that have to be perceived, monitored, and taken into account in decision-making and therefore represents a more complex situation. Based on the aforementioned research, we expect that older drivers' ability to regain vehicle control is disproportionately impaired by high traffic density.

H1: An interaction effect between age and traffic density exists in a way that older drivers' take-over time and quality suffer disproportionately from traffic density. 
This article has been published as Körber, M., Gold, C., Lechner, D., \& Bengler, K. (2016). The influence of age on the take-over of vehicle control in highly automated driving. Transportation Research Part F: Traffic Psychology and Behaviour, 39, 19-32. doi:10.1016/j.trf.2016.03.002

\section{Engagement in a Non-driving Task as Use Case in Highly Automated Driv- ing}

Driving with vehicle automation has been shown to reduce engagement in the driving task (Saxby, Matthews, Warm, Hitchcock, \& Neubauer, 2013) and investigations on drivers' behavior have supported this: Jamson and colleagues (Jamson, Merat, Carsten, \& Lai, 2013) reported that vehicle automation increased the inclination to engage in non-driving activities, i.e. use of in-vehicle entertainment. Carsten and colleagues (Carsten, Lai, Barnard, Jamson, \& Merat, 2012) found that engagement in non-driving tasks, like reading or usage of a DVD player, increased from manual to highly automated driving as a substitution for the vehicle control task. Llaneras, Salinger and Green (2013) reported similar results with engagements like eating or e-mailing. Summed up, engagement in a non-driving task is very likely in highly automated driving. Engagement in a such a task promotes an orientation of attention away from the traffic scene, occupies working memory and thereby promotes a loss of situation awareness (Baumann, Rösler, \& Krems, 2007). If the driver is engaged in a secondary task while being requested to take over, he first has to reallocate attention to the traffic scene, regain situation awareness and then switch to the driving task in order to commence a reaction. The influence of engagement in a secondary task on take-over time has already been investigated empirically: PetermannStock and colleagues (Petermann-Stock et al., 2013) manipulated the task demand of a secondary task and found significant differences in take-over time according to the task demand. The distraction does not have to be visual; a cognitive secondary task can be equally influencing (Radlmayr et al., 2014). This includes having a phone conversation while driving highly automated, which will be a common use case in the future (Kyriakidis, Happee, \& Winter, 2015). However, the influence of this type of nondriving-related task is not well studied yet. Merat and colleagues (Merat, Jamson, Lai, \& Carsten, 2012) simulated a phone conversation by using the 20-Questions Task (TQT), a verbal guessing task with quantifiable performance. The results showed that in the absence of the TQT, response to a critical event was similar for manual and highly automated conditions, but the worst performance occurred when drivers were required to regain vehicle control in the automated condition while being engaged with the TQT. In this study, we investigate the use case phone conversation as engagement in a nondriving task further and simulate a phone conversation as well by means of the TQT. Several authors have examined an age-related decline in cognitive functions that are relevant for the take-over process in case of task engagement and that indicate a possible interaction between age and task engagement: Ponds et al. (1988) showed that elderly adults have a decreased ability to divide attention compared to young and middle-aged adults and dual-task performance of the elderly is worse (Baldwin \& Schieber, 1995; Hartley \& Little, 1999). They have a reduced ability to flexibly allocate attention between two tasks and to adhere to a prioritized focus (Siu, Chou, Mayr, van Donkelaar, \& Woollacott, 2008) and their working memory and thereby their ability to keep relevant situational information active is deteriorated (Salthouse, 1991). Moreover, they have deficits in maintaining and selecting task sets, and also in task switching (Kray, Eber, \& Lindenberger, 2004; Kray \& Lindenberger, 2000; Mayr, 2001). Accordingly, older people need longer to resume a task when they get interrupted (Monk, Boehm-Davis, \& Trafton, 2004). Therefore, we expect that older drivers have increased difficulties to take-over when they are engaged in a non-driving task. The following relationship is expected:

H2: An interaction effect between age and engagement in an additional task exists in a way that older drivers' take-over time and quality suffer disproportionately from engagement in an additional task. 
This article has been published as Körber, M., Gold, C., Lechner, D., \& Bengler, K. (2016). The influence of age on the take-over of vehicle control in highly automated driving. Transportation Research Part F: Traffic Psychology and Behaviour, 39, 19-32. doi:10.1016/j.trf.2016.03.002

\section{Method}

\subsection{Sample}

A total of 72 participants took part in this experiment, 14 (19.4\%) female and 58 (80.6\%) male. Mean age of the young driver group $(n=36)$ was $M=23.28$ years $(S D=2.60)$ with a range from 19 to 28 years. Mean age of the old driver group $(n=36)$ was $M=66.67$ years $(S D=4.56)$ with a range from 60 to 79 years. The possession of a driving license for at least one year was required for participation and participants held their license for a mean of $M=4.34(S D=2.38)$ years in the young driver group and $M=48.44(S D=4.70)$ years in the old driver group. Annual mileage by age group is listed in Table 1. In an interview, no participant reported impairments that could interfere with a driving task.

Table 1. Annual mileage in kilometers by age group.

\begin{tabular}{lcccc}
\hline & $<5,000$ & $5,000-10,000$ & $10,000-20,000$ & $>20,000$ \\
\hline Younger Drivers & 20 & 10 & 5 & 1 \\
Older Drivers & 3 & 8 & 18 & 7 \\
Total & 23 & 18 & 23 & 8 \\
\hline
\end{tabular}

\subsection{Study Design and Measures}

A $2 \times 2 \times 3$ factorial design with the between-subject factors age and task and a within-subject factor traffic density (TD) was used for this experiment. The participants of the older and younger group either drove with or without an additional non-driving task and experienced three take-over situations, each with a different traffic density. The sequence of traffic density conditions was permutated in Latin square design and the participants were evenly distributed on the conditions. Table 2 shows an overview of the experimental conditions.

Table 2. Overview of the experimental conditions.

\begin{tabular}{llccccc}
\hline $\mathrm{Be}$ & \multicolumn{2}{c}{ Younger Drivers } & \multicolumn{3}{c}{ Older drivers } \\
\hline $\mathrm{Be}$ & Task & \multicolumn{2}{c}{ No Task } & Task & No Task \\
\hline Wi & Zero TD & Medium TD & High TD & Zero TD & Medium TD & High TD \\
& & & & & \\
\hline
\end{tabular}

Note. $T D=$ traffic density; $B e=$ between-subject factor; $W i$ = within-subject factor .

Dependent variables were take-over time, minimum time-to-collision (TTC), maximum lateral and maximum longitudinal acceleration. According to previous publications (e.g. Gold, Damböck, Lorenz, \& Bengler, 2013), take-over time was defined as the time between the TOR and the first conscious reaction by the driver, i.e. a change of $10 \%$ of the maximum brake pedal position or more than 2 degrees in steering wheel angle. Besides take-over time, the quality of the take-over is a crucial determinant of a safe reaction to a critical event. Take-over quality is measured in this study by the maximum longitudinal accelerations or the maximum lateral accelerations of the ego vehicle that occurred between the TOR and 166 meters after the obstacle. This interval captures the evasive maneuver as well as the stabilization on the new lane. Additionally, we calculated the time to collision (TTC), which represents the time remaining until a collision with an obstacle is imminent. Hereby, a constant speed difference between vehicle and obstacle is assumed. The TTC decreases until the participant brakes or changes lanes, whereas a TTC of zero represents a collision. The last indicator for take-over quality was the type of resolution of the situation, i.e. if and what kind of collision occurred. Table 3 summarizes the dependent variables. 
This article has been published as Körber, M., Gold, C., Lechner, D., \& Bengler, K. (2016). The influence of age on the take-over of vehicle control in highly automated driving. Transportation Research Part F: Traffic Psychology and Behaviour, 39, 19-32. doi:10.1016/j.trf.2016.03.002

Table 3. Overview of the dependent variables in this study.

\begin{tabular}{lcll}
\hline \multicolumn{1}{c}{ Variable } & Unit & Construct & \multicolumn{1}{c}{ Definition } \\
\hline Take-Over Time & {$[\mathrm{s}]$} & Take-Over Time & $\begin{array}{l}\text { Time between TOR and } \\
\text { start of maneuver }\end{array}$ \\
\hline $\begin{array}{l}\text { Maximum longitudinal } \\
\text { accelerations }\end{array}$ & {$\left[\mathrm{m} / \mathrm{s}^{2}\right]$} & Take-Over Quality & $\begin{array}{l}\text { Max. long. acc. occurred } \\
\text { within the situation }\end{array}$ \\
\hline $\begin{array}{l}\text { Maximum lateral accel- } \\
\text { erations }\end{array}$ & {$\left[\mathrm{m} / \mathrm{s}^{2}\right]$} & Take-Over Quality & $\begin{array}{l}\text { Max. lat. acc. occurred } \\
\text { within the situation }\end{array}$ \\
\hline $\begin{array}{l}\text { Minimal Time-to-Colli- } \\
\text { sion (TTC) }\end{array}$ & {$[\mathrm{s}]$} & Take-Over Quality & $\begin{array}{l}\text { Minimal TC occurred } \\
\text { within situation }\end{array}$ \\
\hline Solution of Situation & count & $\begin{array}{l}\text { Count of collisions in } \\
\text { consequence of the } \\
\text { take-over }\end{array}$ \\
\hline
\end{tabular}

\subsection{Apparatus}

\subsubsection{Driving Simulator and Experimental Track}

The experiment was conducted in a static driving simulator consisting of a BMW 6 series mockup with a front field view of approximately $180^{\circ}$ as well as three additional screens for rear mirrors. SILAB by WIVW GmbH was used to create the driving simulation. Data (vehicle's position, acceleration, steering wheel angle and position of pedals) are recorded at a frequency of $100 \mathrm{~Hz}$. Participants drove highly automated (Gasser, 2012; Level 3 in NHTSA, 2013) at a speed of $120 \mathrm{~km} / \mathrm{h}$ on a six-lane highway (three lanes in each direction). The implemented automation carried out longitudinal and lateral control. Longitudinal control was designed like an ACC system and the automation was able to follow indicated speed limits, to keep the vehicle in the middle of the current lane and to overtake slower vehicles. The initial ego vehicle's lane was permutated in a Latin square design. The system limits were each represented by a broken down vehicle on the participant's current lane. This obstacle suddenly appeared 233 meters ahead on a straight stretch, which made it impossible for the participants to foresee the take-over situation. Also, the situations evolved out of a common traffic flow, for instance, the egovehicle overtook a slower vehicle and, therefore, changed to the lane with the obstacle, which also hindered anticipation of the take-over situations based on traffic or ego-vehicle behavior. Seven seconds before the ego vehicle would have collided with the obstacle, vehicle automation was turned off, i.e. longitudinal and lateral control was transitioned back to the driver, resulting in a drag torque of $0.64 \mathrm{~m} / \mathrm{s}^{2}$. At this particular point in time, an auditory TOR in form of a doubled beep $(2800 \mathrm{~Hz}, 74 \mathrm{~dB}$ ) was given and the driver was requested to take over vehicle control.

\subsubsection{Additional Task}

We simulated a hands-free cell phone conversation by means of the 20 questions task (TQT) which has been shown to induce cognitive distraction in the same manner as a natural cell phone conversation (Heenan, Herdman, Brown, \& Robert, 2014). The participants had to guess an animal by asking a maximum of 20 questions to the experimenter by a microphone in the mockup. Participants were engaged in the task during the whole experimental drive. 
This article has been published as Körber, M., Gold, C., Lechner, D., \& Bengler, K. (2016). The influence of age on the take-over of vehicle control in highly automated driving. Transportation Research Part F: Traffic Psychology and Behaviour, 39, 19-32. doi:10.1016/j.trf.2016.03.002

\subsubsection{Traffic Density Conditions}

In this experiment, three traffic density (TD) conditions were simulated. In Zero TD (TD 0) no other vehicles were on the road at the moment of the take-over situation. For the other two conditions, traffic density was manipulated by the number of other vehicles and their constant and equal distance to the ego vehicle. Condition Medium TD (TD 10) was set with 10 vehicles per kilometer and lane; other road users surrounded the ego vehicle with a distance of approximately $100 \mathrm{~m}$. High TD (TD 20) was set with 20 vehicles per kilometer and lane with a distance of $50 \mathrm{~m}$. In each condition, other vehicles' speed was set equal to the automated ego vehicle. When the TOR was given, other vehicles formed a gap next to the participant's vehicle to enable a lane change as an evasive maneuver.

\subsection{Procedure}

After being welcomed by the experimenter, the participants filled out a demographic entry questionnaire about age, gender and driving experience. An introduction to the experiment and the automation was presented in which they were told that the automation will carry out longitudinal and lateral control and does not have to be monitored, although there are situations that the automation cannot solve. In this case, the TOR warns the driver and he has to regain control. Depending on the condition, the TQT was explained. Next, the driving simulator was shown to the participants and an introductory drive was started. When the participant indicated that he/she felt comfortable using the simulator, the experimental drive was started. The participants then received their reward and were said goodbye. Total time of the experimental session was approximately $80 \mathrm{~min}$.

\section{Results}

To analyze the influence of the independent variables, we conducted a three-way ANOVA with the factors age, task and traffic density for each dependent variable.

\subsection{Take-over Time}

The mean take-over times of the different conditions are listed in Table 4. Table 5 shows the results of the three-way ANOVA for the take-over time. No significant effect was found for age, task or interactions with age or task. However, we found a significant effect for traffic density. Performed post hoc tests using Bonferroni-Holm correction (Holm, 1979) revealed that the zero traffic density condition differed significantly from the medium $(p<.001)$ and high $(p<.001)$ traffic density condition. There was no significant difference between medium and high traffic density $(p=.583)$. Figure 1 and Figure 2 visualize these results. 
This article has been published as Körber, M., Gold, C., Lechner, D., \& Bengler, K. (2016). The influence of age on the take-over of vehicle control in highly automated driving. Transportation Research Part F: Traffic Psychology and Behaviour, 39, 19-32. doi:10.1016/j.trf.2016.03.002

Table 4. Mean take-over time and according confidence interval for each condition.

\begin{tabular}{|c|c|c|c|c|c|c|}
\hline & & & \multirow{2}{*}{$M$} & \multirow{2}{*}{$S D$} & \multicolumn{2}{|c|}{$95 \% \mathrm{Cl}$} \\
\hline & & & & & Lower Limit & Upper Limit \\
\hline \multirow{6}{*}{$\begin{array}{l}\text { Younger } \\
\text { Drivers }\end{array}$} & \multirow{3}{*}{ No Task } & TD 0 & 2.58 & 0.97 & 2.09 & 3.06 \\
\hline & & TD 10 & 3.32 & 1.44 & 2.61 & 4.03 \\
\hline & & TD 20 & 3.52 & 1.17 & 2.94 & 4.10 \\
\hline & \multirow{3}{*}{ Task } & TD 0 & 2.76 & 0.88 & 2.32 & 3.19 \\
\hline & & TD 10 & 3.70 & 0.97 & 3.22 & 4.18 \\
\hline & & TD 20 & 3.66 & 1.24 & 3.04 & 4.28 \\
\hline \multirow{6}{*}{$\begin{array}{l}\text { Older } \\
\text { Drivers }\end{array}$} & \multirow{3}{*}{ No Task } & TD 0 & 2.41 & 1.00 & 1.91 & 2.91 \\
\hline & & TD 10 & 3.41 & 1.34 & 2.74 & 4.08 \\
\hline & & TD 20 & 3.41 & 1.39 & 2.72 & 4.10 \\
\hline & \multirow{3}{*}{ Task } & TD 0 & 2.62 & 1.29 & 1.95 & 3.29 \\
\hline & & TD 10 & 3.25 & 1.41 & 2.53 & 3.97 \\
\hline & & TD 20 & 3.56 & 1.10 & 3.01 & 4.10 \\
\hline
\end{tabular}

Note. Unit of measurement: seconds.

Table 5. Results of an ANOVA on take-over time.

\begin{tabular}{lcccc}
\hline & $F$ & $d f$ & Partial $\eta^{2}$ & $p$ \\
\hline Age & 0.66 & 1,67 & .01 & .420 \\
Task & 0.69 & 1,67 & .01 & .409 \\
Traffic Density & $14.83^{* * *}$ & 2,134 & .18 & $<.001$ \\
Age x Task & 0.21 & 1,67 & .00 & .650 \\
Age x Traffic Density & 0.20 & 2,134 & .00 & .982 \\
Task x Traffic Density & 0.03 & 2,134 & .00 & .974 \\
Age x Task x Traffic Density & 0.38 & 2,134 & .01 & .688 \\
\hline
\end{tabular}

Note. ${ }^{* * *} p<.001$.

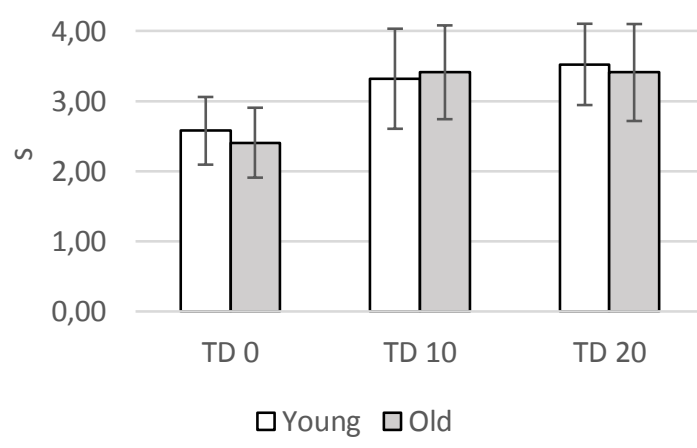

Figure 1. Take-over time of participants without additional task; error bars $=95 \%$ confidence interval.

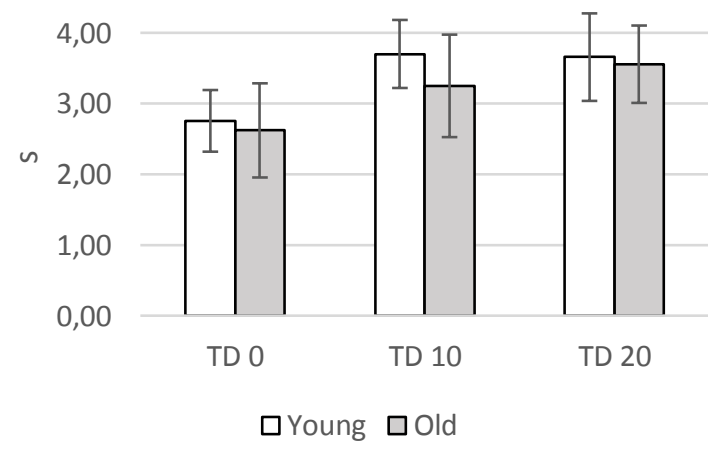

Figure 2. Take-over time of participants with additional task; error bars $=95 \%$ confidence interval. 
This article has been published as Körber, M., Gold, C., Lechner, D., \& Bengler, K. (2016). The influence of age on the take-over of vehicle control in highly automated driving. Transportation Research Part F: Traffic Psychology and Behaviour, 39, 19-32. doi:10.1016/j.trf.2016.03.002

\subsection{Take-over Quality}

In the traffic density conditions TD 10 respectively TD 20, 8 respectively 9 participants caused an accident during the take-over, which is why we can only report take-over time for them. Of these 17 collisions, 8 were collisions with other road users, 6 were collisions with obstacles and in 3 cases the participant left the road. The total frequency of collisions was compared between the two age groups by a chi-squared test, which returned no significant effect $\left(\chi^{2}(1)=0.59, p<.443 ; \mathrm{OR}_{\text {young/old }}=1.42[0.52\right.$, $3.86])$. Table 6 lists the collisions in condition of age group and traffic density.

Table 6. Count of collisions by traffic density and age group.

\begin{tabular}{lccccccccccc}
\hline & & TD 0 & \multicolumn{3}{c}{ TD 10 } & \multicolumn{3}{c}{ TD 20 } & \multirow{2}{*}{ Total } \\
& Obstacle & Traffic & Road & Obstacle & Traffic & Road & Obstacle & Traffic & Road & \\
\hline Young & 0 & 0 & 0 & 2 & 1 & 1 & 3 & 2 & 1 & 10 \\
Old & 0 & 0 & 0 & 0 & 4 & 0 & 1 & 1 & 1 & 7 \\
Total & 0 & 0 & 0 & 2 & 5 & 1 & 4 & 3 & 2 & 17 \\
\hline
\end{tabular}

Next, we investigated the effect on the minimum TTC. We found significant main effects for the factors age, task and traffic density (Table 7). Performed post hoc tests with Bonferroni-Holm correction revealed significantly lower TTCs in medium traffic density $(p<.001)$ compared to zero traffic density as well as significantly lower TTCs in high traffic density $(p<.001)$ compared to zero traffic density, but no significant difference between medium and high traffic density $(p=.144)$. Figure 3 and Figure 4 show these results graphically. Beyond that, the frequency of participants with a TTC lower than 1 second is listed by age group in Table 8 . We found that, compared to the older drivers group, significantly more participants in the younger drivers group kept a TTC below 1 second in TD $20\left(\chi^{2}(1)=4.72\right.$, $\left.p<.03 ; \mathrm{OR}_{\text {young } / \text { old }}=3.44[1.10,10.78]\right)$. The same tendency was found across all traffic densities $\left(\chi^{2}(1)\right.$ $\left.=2.82, p<.093 ; \mathrm{OR}_{\text {young/old }}=1.84[0.90,3.76]\right)$.

Table 7. Results of an ANOVA on minimum TTC.

\begin{tabular}{lcccc}
\hline & $F$ & $d f$ & Partial $^{2}$ & $p$ \\
\hline Age & $5.19^{*}$ & 1,50 & .09 & .027 \\
Task & $5.53^{*}$ & 1,50 & .10 & .023 \\
Traffic Density & $18.48^{* * *}$ & 2,100 & .27 & $<.001$ \\
Age x Task & 0.00 & 1,50 & .00 & .981 \\
Age x Traffic Density & 0.23 & 2,100 & .01 & .793 \\
Task x Traffic Density & 0.05 & 2,100 & .00 & .954 \\
Age x Task x Traffic Density & 0.75 & 2,100 & .02 & .475 \\
\hline
\end{tabular}

Note. ${ }^{*} p<.05 ;{ }^{* * *} p<.001$.

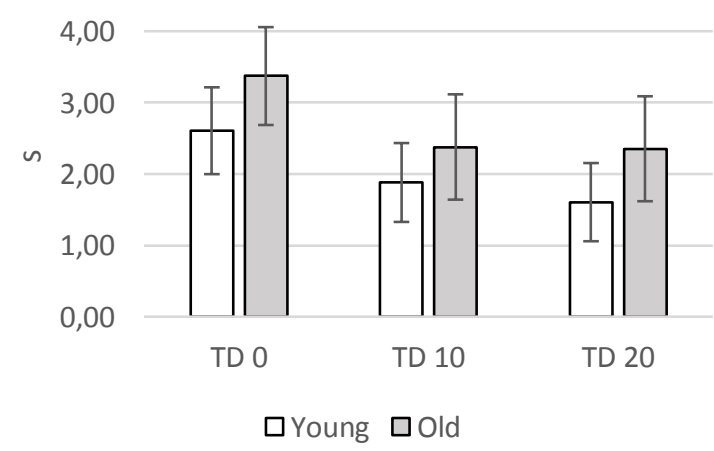

task; error bars $=95 \%$ confidence interval.

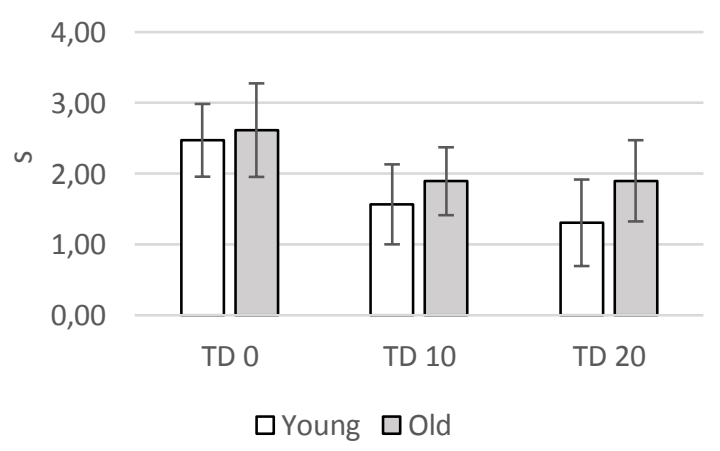

task; error bars $=95 \%$ confidence interval. 
This article has been published as Körber, M., Gold, C., Lechner, D., \& Bengler, K. (2016). The influence of age on the take-over of vehicle control in highly automated driving. Transportation Research Part F: Traffic Psychology and Behaviour, 39, 19-32. doi:10.1016/j.trf.2016.03.002

Table 8. Count of participants with min TTC lower than 1 second by traffic density and age group.

\begin{tabular}{lccccc}
\hline & TD 0 & TD 10 & TD 20 & $\begin{array}{c}\text { At least in } \\
\text { one TD }\end{array}$ & Total \\
\hline Young & $2(34)$ & $9(23)$ & $13(17)$ & $16(10)$ & $24(74)$ \\
Old & $4(32)$ & $5(26)$ & $6(27)$ & $12(16)$ & $15(85)$ \\
Total & $6(66)$ & $14(49)$ & $19(44)$ & $28(26)$ & $39(159)$ \\
$\chi^{2}(1)$ & 0.73 & 1.31 & $4.72^{*}$ & 1.89 & 2.82 \\
OR $_{\text {young/old }}$ & 0.47 & 2.04 & 3.44 & 2.13 & $1.84^{\circ}$ \\
& {$[0.08,2.75]$} & {$[0,606.95]$} & {$[1.10,10.78]$} & {$[0.72,6.33]$} & {$[0.90,3.76]$} \\
logOR & -0.75 & 0.71 & 1.24 & 0.76 & 0.61 \\
& {$[-2.52,1.01]$} & {$[-0.52,1.94]$} & {$[0.09,2.38]$} & {$[-0.33,1.85]$} & {$[-0.11,1.33]$} \\
\hline Note. ${ }^{\circ} p<.10 ;{ }^{*} p<.05 ;$ numbers in parentheses indicate the number of participants with min TC higher than 1 second.
\end{tabular}

To further investigate the differences in minimum TTC, the frequency of engagement in braking was compared between the age groups (Table 9). We found that, compared to the younger drivers group, significantly more participants in the older drivers group engaged in braking in TD $0\left(\chi^{2}(1)=12.41\right.$, $\left.p<.001 ; \mathrm{OR}_{\text {old } / \text { oung }}=6.29[2.17,18.24]\right), \operatorname{TD} 10\left(\chi^{2}(1)=4.60, p=.032 ; \mathrm{OR}_{\text {old } / \text { young }}=3.03[1.09,8.46]\right)$ and across all traffic densities $\left(\chi^{2}(1)=8.66, p=.003 ; \mathrm{OR}_{\text {old } / \text { young }}=2.35[1.32,4.17]\right)$

Table 9. Count of participants that engaged in braking during the take-over maneuver.

\begin{tabular}{|c|c|c|c|c|}
\hline & TD 0 & TD 10 & TD 20 & Total \\
\hline Young & $7(28)$ & $12(20)$ & $16(14)$ & $35(62)$ \\
\hline Old & $22(14)$ & $20(11)$ & $15(18)$ & $57(43)$ \\
\hline Total & $29(42)$ & $32(31)$ & $31(32)$ & $92(105)$ \\
\hline$\chi^{2}(1)$ & $12.41^{* * *}$ & $4.60^{*}$ & 0.39 & $8.66 * *$ \\
\hline OR $_{\text {old/young }}$ & $6.29[2.17,18.24]$ & $3.03[1.09,8.46]$ & $0.73[0.27,2.00]$ & $2.35[1.32,4.17]$ \\
\hline $\log O R_{\text {old/young }}$ & $1.84[0.77,2.90]$ & $1.11[0.08,2.14]$ & $-0.32[-1.31,0.68]$ & $0.85[0.28,1.43]$ \\
\hline
\end{tabular}

After that, we investigated differences in maximum longitudinal acceleration as the second criterion for take-over quality. An ANOVA revealed a significant interaction effect between the factors age and traffic density. Analysis of the group means indicated that younger drivers brake as strong as older participants, but only in the high traffic density condition (Table 10; Figure 5; Figure 6). 
This article has been published as Körber, M., Gold, C., Lechner, D., \& Bengler, K. (2016). The influence of age on the take-over of vehicle control in highly automated driving. Transportation Research Part F: Traffic Psychology and Behaviour, 39, 19-32. doi:10.1016/j.trf.2016.03.002

Table 10. Results of an ANOVA on maximum longitudinal acceleration.

\begin{tabular}{lcccc}
\hline & $F$ & $d f$ & Partial $\eta^{2}$ & $p$ \\
\hline Age & 2.78 & 1,50 & .05 & .102 \\
Task & 0.82 & 1,50 & .02 & .369 \\
Traffic Density & 2.16 & 2,100 & .04 & .113 \\
Age x Task & 0.90 & 2,100 & .02 & .347 \\
Age x Traffic Density & $5.27^{*}$ & 2,100 & .10 & .020 \\
Task x Traffic Density & 0.10 & 2,100 & .00 & .991 \\
Age x Task x Traffic Density & 0.23 & 2,100 & .00 & .789 \\
\hline
\end{tabular}

Note. ${ }^{*} p<.05$.

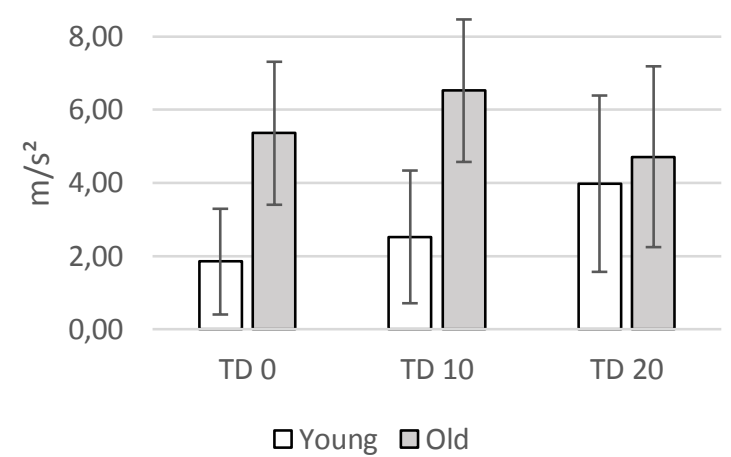

Figure 5. Maximum longitudinal acceleration of participants without additional task; error bars $=95 \%$ confidence interval.

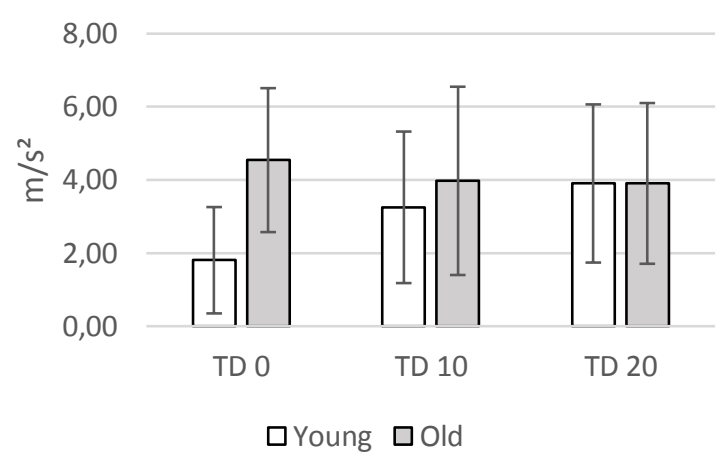

Figure 6. Maximum longitudinal acceleration of participants with additional task; error bars $=95 \%$ confidence interval.

As the third criterion for take-over quality, we analyzed the maximum lateral acceleration (Table 11; Figure 7; Figure 8). There was no significant difference between the age groups and no interaction effect with age. We found a significant effect for traffic density. Performed post hoc tests using Bonferroni-Holm correction revealed a significant difference between zero traffic density and medium traffic density $(p=.047)$ and a significant difference between zero traffic density and high traffic density $(p<.001)$. No difference was found between the medium and high traffic density condition $(p=.279)$.

Table 11. Results of an ANOVA on maximum lateral acceleration.

\begin{tabular}{lcccc}
\hline & $F$ & $d f$ & Partial $^{2}$ & $p$ \\
\hline Age & .09 & 1,50 & .00 & .771 \\
Task & 2.62 & 1,50 & .05 & .112 \\
Traffic Density & $6.48^{* *}$ & 1,100 & .12 & .002 \\
Age x Task & .09 & 1,50 & .00 & .772 \\
Age x Traffic Density & 0.16 & 2,100 & .00 & .853 \\
Task x Traffic Density & 1.73 & 2,100 & .03 & .182 \\
Age x Task x Traffic Density & 0.06 & 2,100 & .00 & .939 \\
\hline
\end{tabular}

Note. ${ }^{* *} p<.01$. 
This article has been published as Körber, M., Gold, C., Lechner, D., \& Bengler, K. (2016). The influence of age on the take-over of vehicle control in highly automated driving. Transportation Research Part F: Traffic Psychology and Behaviour, 39, 19-32. doi:10.1016/j.trf.2016.03.002

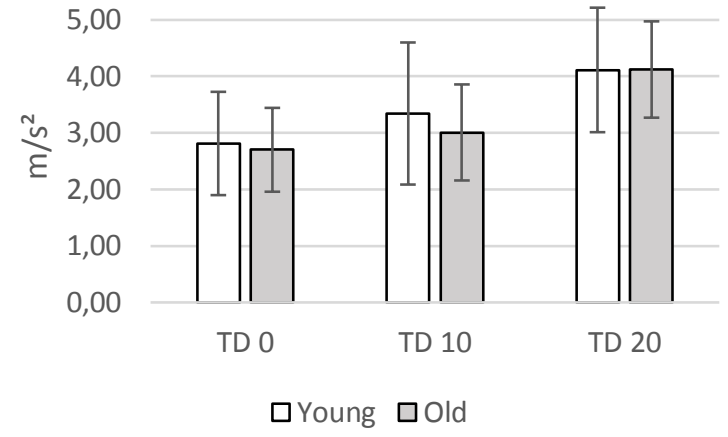

Figure 7. Maximum lateral acceleration of participants without additional task; error bars $=95 \%$ confidence interval.

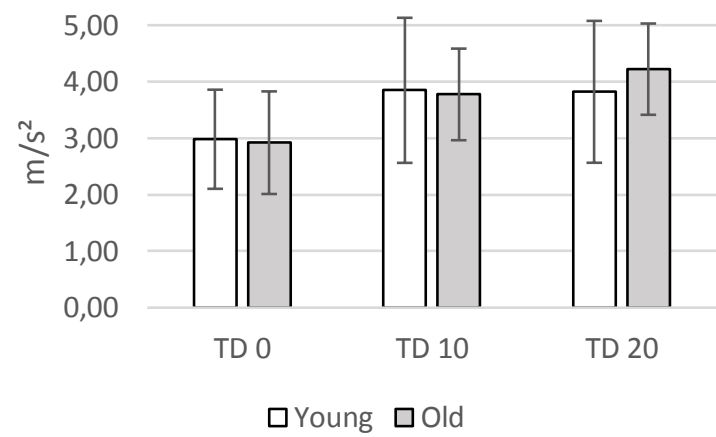

Figure 8. Maximum lateral acceleration of participants with additional task; error bars $=95 \%$ confidence interval.

To investigate if both age groups show the same adaption to the take-over situations, we conducted an ANOVA with the factors number of situation, age and traffic density (Table 12; Figure 9; Figure 10) and take-over time as the dependent variable. We found a significant effect for the number of the situation and post hoc tests using Bonferroni-Holm correction revealed a significant difference between the first and the second situation $(p=.001)$ and a difference between the first and the third situation $(p<.001)$. There was no significant difference between the second and third situation $(p=.171)$. Age had no influence on this learning effect. Similar to previous analysis, post hoc tests for traffic density revealed a difference between the zero traffic density condition and medium traffic density $(p<.001)$ as well as high traffic density $(p<.001)$, but no significant difference between the medium and high traffic density condition ( $p=.529)$. The minimum TTC increased independently of age and traffic density from $M=1.90(S D=1.11)$ in Situation 1 to $M=2.43(S D=1.34)$ in Situation 3. We obtained a linear trend for this increase $(F(1,56)=5.30, p=.025)$, however, a repeated measures ANOVA indicated only a trend for differences between the means $(F(2,112)=2.87, p=.061)$. A repeated measures ANOVA revealed no significant differences between the means of the situations in maximum longitudinal accelerations $(F(2,112)=0.23, p=.792)$ as well. The mean maximum lateral acceleration decreased from $M=4.05(S D=2.09)$ in Situation 1 to $M=2.98(S D=1.68)$ in Situation 3. $A$ repeated measures ANOVA revealed a significant differences between the means of the Situations $(F(2,112)=8.05, p=.001)$ and this decrease appeared in a linear manner $(F(1,56)=15.77, p<.001)$. Post hoc tests with Bonferroni-Holm correction revealed a significant difference between Situation 1 and $2(p=.018)$ and between Situation 1 and $3(p<.001)$, but not between Situation 2 and $3(p=.265)$. This effect occurred independently of age and traffic density.

Table 12. Results of an ANOVA on take-over time to investigate the learning effect in the course of the experiment.

\begin{tabular}{lcccc}
\hline & $F$ & $d f$ & Partial $\eta^{2}$ & $p$ \\
\hline Situation & $13.78^{* * *}$ & 2,130 & .18 & $<.001$ \\
Age & 2.76 & 1,65 & .04 & .102 \\
Traffic Density & $18.67^{* * *}$ & 2,65 & .37 & $<.001$ \\
Age x Traffic Density & 0.02 & 2,65 & .00 & .978 \\
Situation x Traffic Density & 1.03 & 4,130 & .03 & .395 \\
Situation x Age & 0.67 & 2,130 & .01 & .515 \\
Situation x Age x Traffic Density & $2.53^{*}$ & 4,130 & .07 & .044 \\
\hline
\end{tabular}

Note. ${ }^{*} p<.05 ;{ }^{* * *} p<.001$. 
This article has been published as Körber, M., Gold, C., Lechner, D., \& Bengler, K. (2016). The influence of age on the take-over of vehicle control in highly automated driving. Transportation Research Part F: Traffic Psychology and Behaviour, 39, 19-32. doi:10.1016/j.trf.2016.03.002

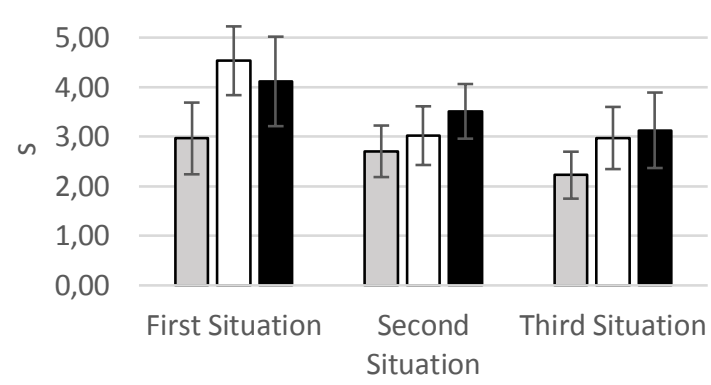

口TD 0 पTD $10 \boldsymbol{\square T D} 20$

Figure 9. Take-over time of younger drivers in condition of the number of experienced situations; error bars $=95 \%$ confidence interval.

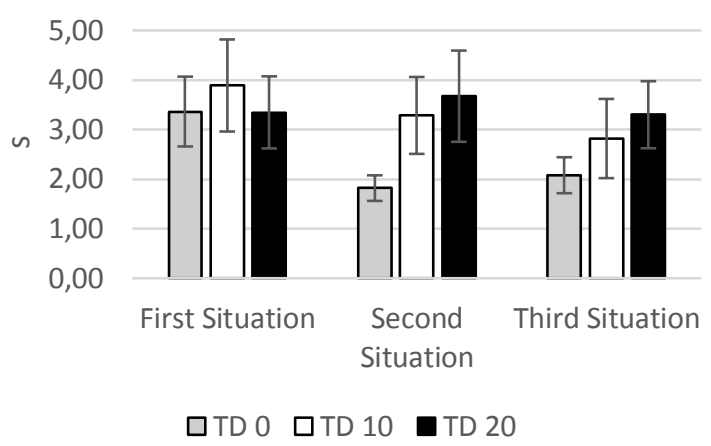

Figure 10. Take-over time of older drivers in condition of the number of experienced situations; error bars $=95 \%$ confidence interval.

\section{Discussion}

In this study, we investigated the influence of age on take-over time and take-over quality in different traffic densities and in combination with a non-driving task. The confidence intervals of take-over time show a high overlap and no significant difference between younger and older drivers was found: despite the mentioned expected decline in cognitive performance, older participants reacted as fast as young participants. This is consistent with a similar, previous study by Petermann-Stock et al. (2013) and although both studies are not fully comparable, we obtained similar results: Our results on mean take-over time for participants with an additional task differ $210 \mathrm{~ms}$ for younger drivers and $240 \mathrm{~ms}$ for older drivers from their study (180 ms for younger drivers and 70 ms for older drivers for mean standard deviation). However, contrary to our findings, laboratory reaction time tests suggest an increase in reaction times with increasing age (Der \& Deary, 2006; Salthouse, 2009; Yang, Bender, \& Raz, 2015). One possible explanation for the contradictory results could be that the cognitive decline at this age is only observable in laboratory tests and not pronounced enough to matter in an applied task. Laboratory tests are usually conducted under very controlled conditions and require rather simple inputs by the participant; mean reaction times in these tests typically are lower than take-over times and range between $300-800 \mathrm{~ms}$, depending on the test. This procedure leads to highly reliable and reproducible reaction times with low inter-subject variance, which provides the statistical power to detect differences in reaction times between age groups. Coefficients of variation between subjects in comparable age groups in these studies are typically around $18 \%$ for younger participants and $25 \%$ for older participants (Anstey, 1999; Deary et al., 2009; Der \& Deary, 2006; Gorus, Raedt, \& Mets, 2006); while this study's coefficients of variation were $39 \%$ for younger drivers and $35 \%$ for older drivers. Intra-subject variation in this study was higher (32\% for younger drivers, $34 \%$ for older drivers) compared to laboratory tests (around 22\% for younger participants, $24 \%$ for older participants), as well. The difference in variability of performance supports the notion that a naturalistic task like taking over vehicle control might not be sensitive and controlled enough to replicate age-related differences in reaction times. Furthermore, naturalistic tasks involve, in addition to general cognitive abilities, also specific knowledge and expertise (Hertzog et al., 2008). This issue of ecological validity and external validity of laboratory tests has been already discussed in multiple fields (Chapanis, 1967; Hancock, 2013; Hoc, 2001; Tarnanas et al., 2013; Zelditch, 2007). However, reported correlations between reaction time tests and crash involvement support the validity of standardized tests in this case (McKnight \& McKnight, 1999). Given the high variability in cognitive decline (Hultsch et al., 2002), it has to be 
This article has been published as Körber, M., Gold, C., Lechner, D., \& Bengler, K. (2016). The influence of age on the take-over of vehicle control in highly automated driving. Transportation Research Part F: Traffic Psychology and Behaviour, 39, 19-32. doi:10.1016/j.trf.2016.03.002

taken into account that the participants in this study were volunteers who very likely assessed themselves fit enough for a novel task in a driving simulator. A selection bias could be existent in a manner that only cognitively very fit older participants volunteer for such a study and thereby do not represent the general older age population. Regarding the execution of the take-over maneuver (viz. take-over quality), older participants caused fewer collisions and kept a longer minimum TTC in their take-over situations. Also, they braked stronger than younger participants when the traffic density was zero or medium and, in total, older drivers' chance to brake during the take-over was twice as high as younger drivers' chance. This becomes especially clear in the zero traffic condition where the chance to brake was six times higher for older drivers. Accordingly, with their riskier take-over execution, younger drivers had almost two times higher chance to have a TTC below one second. Altogether, the older age group executed a safer and more careful take-over, which could be seen as a consequence of their probably greater driving experience. Younger participants only saw this more conservative strategy as necessary if the traffic density and thereby the complexity of the situation was high. Stronger braking can also be seen as a compensatory behavior which allows the operator more time to react. It is imaginable that younger participants, in contrast to the older driver group, only needed this compensation in the most complex situation. For both age groups, about $10 \%$ of the participants were involved in a collision during the take-over when other road users were present, which highlights the difficulty of taking over in traffic regardless of age.

An additional task neither influenced take-over time for younger nor for older participants, but led to a slightly shorter (497 ms [73, 921]) minimum TTC, thus to a more critical take-over, also independent of the age group. Thus, older participants do not have more problems with an additional task than younger participants. Although Radlmayr and colleagues (Radlmayr et al., 2014) showed, that a cognitive task impairs take-over performance, we could not replicate their findings. A reason for this could be that they used the $n$-back task, which is not interruptible by the participant. The progress in the 20 questions task, which was used in this study, could be controlled by the participants and interrupted at any time, which might result in a lower occupation of working memory - a proposed main factor for age effects in dual-task studies (Salthouse, 1992) - and distraction.

Increased traffic density extended take-over time, increased the number of collisions and decreased minimum TTC for both age groups equally, yet older participants generally tend to show stronger braking while younger participants only showed stronger braking in the high traffic condition. Future studies have to elaborate if this is a compensatory measure because of higher workload caused by the other road users or if it represents a difference in risk perception or driving experience.

Independent of the traffic density, there was a learning effect for both younger and older drivers in a way that the execution of the take-over became less risky between the first and the last situation, which is consistent with past research (Gold \& Bengler, 2014; Petermann-Stock et al., 2013). More precisely, take-over time decreased, minimum TTC increased and maximum lateral acceleration decreased. The reduction of take-over time was stronger for older participants in the zero traffic density condition, probably because they evaluated the situation without other road users as more controllable after experiencing a take-over situation for the first time. Younger participants reduced their takeover time with each situation independently of traffic density.

Overall, the results show that older participants are able to take over as fast and as well as young participants and do not have a disproportional decrease in performance or quality by an additional task or by high situational complexity. Both age groups adapted to the experience of take-over situations in the same way, independently of traffic density: take-over time decreased, minimum TTC increased and maximum lateral acceleration decreased between the first and the last situation of the 
This article has been published as Körber, M., Gold, C., Lechner, D., \& Bengler, K. (2016). The influence of age on the take-over of vehicle control in highly automated driving. Transportation Research Part F: Traffic Psychology and Behaviour, 39, 19-32. doi:10.1016/j.trf.2016.03.002

experiment. However, older drivers generally braked more often and more strongly and maintained a higher TTC in the take-over situations.

It is difficult to generalize these results to the population of older drivers in general since the cognitive decline is highly variable in its degree (Deary et al., 2009; Hultsch et al., 2002; Morse, 1993). Also, as already mentioned, a selection bias might exist in this study so that only cognitively very fit older participants might have taken part. As Hakamies-Blomqvist (1998) claimed, not age in general causes a higher crash risk, but a decline in particular abilities. Factors like personal lifestyle, experiences, and genetics determine the speed of cognitive decline, create an individual variability in it, and, therefore, older drivers at the bottom of the zone of possible functioning (Hertzog et al., 2008) could have solved this situation less successfully, despite being the same age. Given the possibilities of collisions and injuries, we conducted the study in a static driving simulator. Therefore, it was not possible for the participants to feel acceleration and braking and it is imaginable that, because of the lack of consequences, a difference in risky behavior in comparison to a naturalistic drive could exist. However, we used a high-fidelity mockup and simulated a realistic highway drive, which is a possible scenario for the deployment of vehicle automation. Participants were instructed to obey traffic rules and to guarantee safety at any time. We, therefore, believe that the behavior in the experiments reflects realistic behavior.

Future studies could use a visually distracting non-driving-related task to compare the results to this study. Beyond that, naturalistic tasks like a real conversation or office work should be investigated. It could also be interesting if older drivers engage in non-driving activities as much as younger drivers if engagement in a non-driving task is not mandatory. Given that, in this study, older drivers tended to execute the take-over more carefully, differences in engagement and gaze behavior (e.g. monitoring frequency) could exist. It is imaginable that they engage less in non-driving tasks as a form of compensatory behavior and because of safety concerns. Besides age, trust in automation is probably another relevant individual difference, which could influence monitoring behavior and secondary task engagement (Körber \& Bengler, 2014). Mahr and Müller (2011) state in their model that overreliance on an automation because of too much trust leads to a risk adaption, i.e. the driver takes risks he would not take without an automation. Consequences of overreliance are longer reaction times (Beller, Heesen, \& Vollrath, 2013; Helldin, Falkman, Riveiro, \& Davidsson, 2013) or lower reaction quality (McGuirl \& Sarter, 2006) in critical events. Therefore, take-over time and similar dependent variables could be confounded with the trust in automation and statistically controlling this attitude could be a promising way to clarify influence factors in the take-over process in future studies. With increasing life expectancy (Eggleston \& Fuchs, 2012), drivers beyond the age range used in this study (upper end of 79 years of age) are becoming more common. Therefore, it is reasonable to include drivers above the age of 80 years in a future study. This could be conducted by using standard driving ability assessment tests to select elderly drivers that have sufficient abilities to take part in traffic, but still deviate from younger participants.

\section{Acknowledgements}

The opportunity to conduct this study was granted by the interdisciplinary sociotechnical research program ASHAD (Automation in Society - Highly Automated Driving) of the Munich Center for Technology and Society, Technische Universität München.

\section{References}

Andrews, E. C., \& Westerman, S. J. (2012). Age differences in simulated driving performance: compensatory processes. Accident Analysis \& Prevention, 45, 660-668. doi:10.1016/j.aap.2011.09.047 
This article has been published as Körber, M., Gold, C., Lechner, D., \& Bengler, K. (2016). The influence of age on the take-over of vehicle control in highly automated driving. Transportation Research Part F: Traffic Psychology and Behaviour, 39, 19-32. doi:10.1016/j.trf.2016.03.002

Anstey, K. J. (1999). Sensorimotor Variables and Forced Expiratory Volume as Correlates of Speed, Accuracy, and Variability in Reaction Time Performance in Late Adulthood. Aging, Neuropsychology, and Cognition (Neuropsychology, Development and Cognition: Section B), 6(2), 84-95. doi:10.1076/anec.6.2.84.786

Anstey, K. J., Wood, J., Lord, S., \& Walker, J. G. (2005). Cognitive, sensory and physical factors enabling driving safety in older adults. Clinical psychology review, 25(1), 45-65. doi:10.1016/j.cpr.2004.07.008

Baldwin, C. L., \& Coyne, J. T. (2003). Mental workload as a function of traffic density: Comparison of physiological, behavioral, and subjective indices. In E. Hollnagel, A. Nåbo, \& I. V. Lau (Eds.), Proceedings of the Second International Driving Symposium on Human Factors in Driver Assessment, Training and Vehicle Design (pp. 19-24).

Baldwin, C. L., \& Schieber, F. (1995). Dual Task Assessment of Age Differences in Mental Workload with Implications for Driving. Proceedings of the Human Factors and Ergonomics Society Annual Meeting, 39(2), 167-171. doi:10.1177/154193129503900210

Baltes, P. B., Staudinger, U. M., \& Lindenberger, U. (1999). Lifespan Psychology: Theory and Application to Intellectual Functioning. Annual Review of Psychology, 50(1), 471-507. doi:10.1146/annurev.psych.50.1.471

Baumann, M. R. K., Rösler, D., \& Krems, J. F. (2007). Situation Awareness and Secondary Task Performance While Driving. In D. Harris (Ed.), Lecture Notes in Computer Science. Engineering Psychology and Cognitive Ergonomics (Vol. 4562, pp. 256-263). Berlin, Heidelberg: Springer-Verlag Berlin Heidelberg.

Beller, J., Heesen, M., \& Vollrath, M. (2013). Improving the Driver-Automation Interaction: An Approach Using Automation Uncertainty. Human Factors: The Journal of the Human Factors and Ergonomics Society, 55(6), 1130-1141. doi:10.1177/0018720813482327

Blanchard, R. A., Myers, A. M., \& Porter, M. M. (2010). Correspondence between self-reported and objective measures of driving exposure and patterns in older drivers. Accident Analysis \& Prevention, 42(2), 523-529. doi:10.1016/j.aap.2009.09.018

Bryan, J., \& Luszcz, M. A. (2000). Measurement of Executive Function: Considerations for Detecting Adult Age Differences. Journal of Clinical and Experimental Neuropsychology (Neuropsychology, Development and Cognition: Section A), 22(1), 40-55. doi:10.1076/1380-3395(200002)22:1;1$8 ; \mathrm{ft} 040$

Cantin, V., Lavallière, M., Simoneau, M., \& Teasdale, N. (2009). Mental workload when driving in a simulator: Effects of age and driving complexity. Accident Analysis \& Prevention, 41(4), 763-771. doi:10.1016/j.aap.2009.03.019

Carsten, O., Lai, F., Barnard, Y., Jamson, A. H., \& Merat, N. (2012). Control Task Substitution in Semiautomated Driving: Does It Matter What Aspects Are Automated? Human Factors: The Journal of the Human Factors and Ergonomics Society, 54(5), 747-761. doi:10.1177/0018720812460246

Cauley, J. A. (2012). The Demography of Aging. In A. B. Newman \& J. A. Cauley (Eds.), The Epidemiology of Aging (pp. 3-14). Dordrecht: Springer Netherlands.

Chapanis, A. (1967). The relevance of laboratory studies to practical situations. Ergonomics, 10(5), 557-577. doi:10.1080/00140136708930910

Cicchino, J. B., \& McCartt, A. T. (2015). Critical older driver errors in a national sample of serious U.S. crashes. Accident Analysis \& Prevention, 80, 211-219. doi:10.1016/j.aap.2015.04.015

Deary, I. J., Corley, J., Gow, A. J., Harris, S. E., Houlihan, L. M., Marioni, R. E., . . Starr, J. M. (2009). Age-associated cognitive decline. British Medical Bulletin, 92, 135-152. doi:10.1093/bmb/ldp033 
This article has been published as Körber, M., Gold, C., Lechner, D., \& Bengler, K. (2016). The influence of age on the take-over of vehicle control in highly automated driving. Transportation Research Part F: Traffic Psychology and Behaviour, 39, 19-32. doi:10.1016/j.trf.2016.03.002

Der, G., \& Deary, I. J. (2006). Age and sex differences in reaction time in adulthood: results from the United Kingdom Health and Lifestyle Survey. Psychology and Aging, 21(1), 62-73. doi:10.1037/0882-7974.21.1.62

Devlin, A., McGillivray, J., Charlton, J., Lowndes, G., \& Etienne, V. (2012). Investigating driving behaviour of older drivers with mild cognitive impairment using a portable driving simulator. Accident Analysis \& Prevention, 49, 300-307. doi:10.1016/j.aap.2012.02.022

Dotzauer, M., Waard, D. de, Caljouw, S. R., Pöhler, G., \& Brouwer, W. H. (2015). Behavioral adaptation of young and older drivers to an intersection crossing advisory system. Accident Analysis \& Prevention, 74, 24-32. doi:10.1016/j.aap.2014.09.030

Eggleston, K. N., \& Fuchs, V. R. (2012). The New Demographic Transition: Most Gains in Life Expectancy Now Realized Late in Life. The journal of economic perspectives: a journal of the American Economic Association, 26(3), 137-156. doi:10.1257/jep.26.3.137

Fuller, R. (2005). Towards a general theory of driver behaviour. Accident Analysis \& Prevention, 37(3), 461-472. doi:10.1016/j.aap.2004.11.003

Gasser, T. M. (2012). Rechtsfolgen zunehmender Fahrzeugautomatisierung: Gemeinsamer Schlussbericht der Projektgruppe. Berichte der Bundesanstalt für Straßenwesen - Fahrzeugtechnik (F): Vol. 83. Bremerhaven: Wirtschaftsverlag NW.

Gold, C., \& Bengler, K. (2014). Taking Over Control from Highly Automated Vehicles. In N. Stanton, S. Landry, G. Di Bucchianico, \& A. Vallicelli (Eds.): Vol. [8]. Advances in human factors and ergonomics 2014, Advances in human aspects of transportation, Part II (pp. 64-69). Louisville, KY: AHFE Conference.

Gold, C., Damböck, D., Lorenz, L., \& Bengler, K. (2013). "Take over!" How long does it take to get the driver back into the loop? Proceedings of the Human Factors and Ergonomics Society Annual Meeting, 57(1), 1938-1942. doi:10.1177/1541931213571433

Gorus, E., Raedt, R. de, \& Mets, T. (2006). Diversity, dispersion and inconsistency of reaction time measures: Effects of age and task complexity. Aging Clinical and Experimental Research, 18(5), 407-417. doi:10.1007/BF03324837

Haegerstrom-Portnoy, G., Schneck, M. E., \& Brabyn, J. A. (1999). Seeing into Old Age: Vision Function Beyond Acuity. Optometry and Vision Science, 76(3), 141-158. doi:10.1097/00006324-19990300000014

Hakamies-Blomqvist, L. (1998). Older drivers' accident risk: Conceptual and methodological issues. Accident Analysis \& Prevention, 30(3), 293-297. doi:10.1016/S0001-4575(97)00120-6

Hancock, P. A. (2013). In search of vigilance: the problem of iatrogenically created psychological phenomena. The American psychologist, 68(2), 97-109. doi:10.1037/a0030214

Hartley, A. A., \& Little, D. M. (1999). Age-related differences and similarities in dual-task interference. Journal of Experimental Psychology: General, 128(4), 416-449.

Heenan, A., Herdman, C. M., Brown, M. S., \& Robert, N. (2014). Effects of conversation on situation awareness and working memory in simulated driving. Human Factors: The Journal of the Human Factors and Ergonomics Society, 56(6), 1077-1092.

Helldin, T., Falkman, G., Riveiro, M., \& Davidsson, S. (2013). Presenting system uncertainty in automotive Uls for supporting trust calibration in autonomous driving. In J. Terken (Ed.), Proceedings of the 5th International Conference on Automotive User Interfaces and Interactive Vehicular Applications (pp. 210-217). New York, NY: ACM. 
This article has been published as Körber, M., Gold, C., Lechner, D., \& Bengler, K. (2016). The influence of age on the take-over of vehicle control in highly automated driving. Transportation Research Part F: Traffic Psychology and Behaviour, 39, 19-32. doi:10.1016/j.trf.2016.03.002

Hertzog, C. (2008). Theoretical approaches to the study of cognitive aging: An individual differences perspective. In S. M. Hofer \& D. F. Alwin (Eds.), Handbook of cognitive aging. Interdisciplinary perspectives (pp. 34-49). Los Angeles: Sage Publications.

Hertzog, C., Kramer, A. F., Wilson, R. S., \& Lindenberger, U. (2008). Enrichment Effects on Adult Cognitive Development: Can the Functional Capacity of Older Adults Be Preserved and Enhanced? Psychological Science in the Public Interest, 9(1), 1-65. doi:10.1111/j.1539-6053.2009.01034.x

Hoc, J.-M. (2001). Towards ecological validity of research in cognitive ergonomics. Theoretical Issues in Ergonomics Science, 2(3), 278-288. doi:10.1080/14639220110104970

Holm, S. (1979). A simple sequentially rejective multiple test procedure. Scandinavian journal of statistics, 65-70.

Horberry, T., Anderson, J., Regan, M. A., Triggs, T. J., \& Brown, J. (2006). Driver distraction: The effects of concurrent in-vehicle tasks, road environment complexity and age on driving performance. Accident Analysis \& Prevention, 38(1), 185-191. doi:10.1016/j.aap.2005.09.007

Horswill, M. S., Marrington, S. A., McCullough, C. M., Wood, J., Pachana, N. A., McWilliam, J., \& Raikos, M. K. (2008). The hazard perception ability of older drivers. The journals of gerontology. Series $B$, sychological sciences and social sciences, 63(4), 212-218.

Hultsch, D. F., MacDonald, S. W. S., \& Dixon, R. A. (2002). Variability in Reaction Time Performance of Younger and Older Adults. The Journals of Gerontology Series B: Psychological Sciences and Social Sciences, 57(2), 101-115. doi:10.1093/geronb/57.2.P101

Jamson, A. H., Merat, N., Carsten, O., \& Lai, F. (2013). Behavioural changes in drivers experiencing highly-automated vehicle control in varying traffic conditions. Transportation Research Part $C$ : Emerging Technologies, 30, 116-125. doi:10.1016/j.trc.2013.02.008

Körber, M., \& Bengler, K. (2014). Potential Individual Differences Regarding Automation Effects in Automated Driving. In C. S. G. González, C. C. Ordóñez, \& H. Fardoun (Eds.), Interacción 2014: Proceedings of the XV International Conference on Human Computer Interaction (pp. 152-158). New York, NY, USA: ACM.

Kray, J., Eber, J., \& Lindenberger, U. (2004). Age differences in executive functioning across the lifespan: the role of verbalization in task preparation. Acta Psychologica, 115(2-3), 143-165. doi:10.1016/j.actpsy.2003.12.001

Kray, J., \& Lindenberger, U. (2000). Adult age differences in task switching. Psychology and Aging, 15(1), 126-147. doi:10.1037/0882-7974.15.1.126

Kyriakidis, M., Happee, R., \& Winter, J. de. (2015). Public opinion on automated driving: Results of an international questionnaire among 5000 respondents. Transportation Research Part F: Traffic Psychology and Behaviour, 32, 127-140. doi:10.1016/j.trf.2015.04.014

Langford, J., Methorst, R., \& Hakamies-Blomqvist, L. (2006). Older drivers do not have a high crash risk - A replication of low mileage bias. Accident Analysis \& Prevention, 38(3), 574-578. doi:10.1016/j.aap.2005.12.002

Llaneras, R., Salinger, J., \& Green, C. (2013). Human Factors Issues Associated With Limited Ability Autonomous Driving Systems: Drivers' Allocation Of Visual Attention To The Forward Roadway. In Proceedings of the 7th International Driving Symposium on Human Factors in Driver Assessment, Training, and Vehicle Design (pp. 92-98). Iowa City, lowa: The University of lowa, Public Policy Center.

Mahr, A., \& Müller, C. (2011). A Schema of Possible Negative Effects of Advanced Driver Assistant Systems. In Proceedings of the 6th International Driving Symposium on Human Factors in Driver 
This article has been published as Körber, M., Gold, C., Lechner, D., \& Bengler, K. (2016). The influence of age on the take-over of vehicle control in highly automated driving. Transportation Research Part F: Traffic Psychology and Behaviour, 39, 19-32. doi:10.1016/j.trf.2016.03.002

Assessment, Training, and Vehicle Design. Driving assessment 2011, Resort at Squaw Creek, Olympic Valley-Lake Tahoe, California, USA, June 27-30, 2011 (pp. 116-121). lowa City, lowa: The University of lowa, Public Policy Center.

Maltz, M., \& Shinar, D. (1999). Eye Movements of Younger and Older Drivers. Human Factors: The Journal of the Human Factors and Ergonomics Society, 41(1), 15-25. doi:10.1518/001872099779577282

Masunaga, H., \& Horn, J. (2001). Expertise and age-related changes in components of intelligence. Psychology and Aging, 16(2), 293-311. doi:10.1037//0882-7974.16.2.293

Mayr, U. (2001). Age differences in the selection of mental sets: The role of inhibition, stimulus ambiguity, and response-set overlap. Psychology and Aging, 16(1), 96-109. doi:10.1037/08827974.16.1.96

McGuirl, J. M., \& Sarter, N. B. (2006). Supporting Trust Calibration and the Effective Use of Decision Aids by Presenting Dynamic System Confidence Information. Human Factors: The Journal of the Human Factors and Ergonomics Society, 48(4), 656-665. doi:10.1518/001872006779166334

McKnight, A. J., \& McKnight, A. S. (1999). Multivariate analysis of age-related driver ability and performance deficits. Accident Analysis \& Prevention, 31(5), 445-454. doi:10.1016/S00014575(98)00082-7

Merat, N., Jamson, A. H., Lai, F., \& Carsten, O. (2012). Highly Automated Driving, Secondary Task Performance, and Driver State. Human Factors: The Journal of the Human Factors and Ergonomics Society, 54(5), 762-771. doi:10.1177/0018720812442087

Monk, C. A., Boehm-Davis, D. A., \& Trafton, J. G. (2004). Recovering From Interruptions: Implications for Driver Distraction Research. Human Factors: The Journal of the Human Factors and Ergonomics Society, 46(4), 650-663. doi:10.1518/hfes.46.4.650.56816

Morse, C. K. (1993). Does variability increase with age? An archival study of cognitive measures. Psychology and Aging, 8(2), 156-164. doi:10.1037/0882-7974.8.2.156

National Highway Traffic Safety Administration. (2013). Preliminary statement of policy concerning automated vehicles. Washington, DC.

Petermann-Stock, I., Hackenberg, L., Muhr, T., \& Mergl, C. (2013). Wie lange braucht der Fahrer? Eine Analyse zu Übernahmezeiten aus verschiedenen Nebentätigkeiten während einer hochautomatisierten Staufahrt. In 6. Tagung Fahrerassistenz. Der Weg zum automatischen Fahren. TÜV SÜD Akademie $\mathrm{GmbH}$.

Ponds, R. W. H. M., Brouwer, W. H., \& Van Wolffelaar, P. C. (1988). Age Differences in Divided Attention in a Simulated Driving Task. Journal of Gerontology, 43(6), 151-156. doi:10.1093/geronj/43.6.P151

Radlmayr, J., Gold, C., Lorenz, L., Farid, M., \& Bengler, K. (2014). How Traffic Situations and Non-Driving Related Tasks Affect the Take-Over Quality in Highly Automated Driving. Proceedings of the Human Factors and Ergonomics Society Annual Meeting, 58(1), 2063-2067. doi:10.1177/1541931214581434

Salthouse, T. A. (1987). The role of representations in age differences in analogical reasoning. Psychology and Aging, 2(4), 357-362. doi:10.1037/0882-7974.2.4.357

Salthouse, T. A. (1988). The Role of Processing Resources in Cognitive Aging. In C. J. Brainerd \& M. L. Howe (Eds.), Springer Series in Cognitive Development. Cognitive Development in Adulthood (pp. 185-239). New York, NY: Springer New York. 
This article has been published as Körber, M., Gold, C., Lechner, D., \& Bengler, K. (2016). The influence of age on the take-over of vehicle control in highly automated driving. Transportation Research Part F: Traffic Psychology and Behaviour, 39, 19-32. doi:10.1016/j.trf.2016.03.002

Salthouse, T. A. (1991). Mediation of Adult Age Differences in Cognition by Reductions in Working Memory and Speed of Processing. Psychological Science, 2(3), 179-183. doi:10.1111/j.14679280.1991.tb00127.x

Salthouse, T. A. (1992). Why do adult age differences increase with task complexity? Developmental Psychology, 28(5), 905-918. doi:10.1037/0012-1649.28.5.905

Salthouse, T. A. (2009). When does age-related cognitive decline begin? Neurobiology of Aging, 30(4), 507-514. doi:10.1016/j.neurobiolaging.2008.09.023

Saxby, D. J., Matthews, G., Warm, J. S., Hitchcock, E. M., \& Neubauer, C. (2013). Active and passive fatigue in simulated driving: Discriminating styles of workload regulation and their safety impacts. Journal of Experimental Psychology: Applied, 19(4), 287-300. doi:10.1037/a0034386

Scialfa, C. T., Guzy, L. T., Leibowitz, H. W., Garvey, P. M., \& Tyrrell, R. A. (1991). Age differences in estimating vehicle velocity. Psychology and Aging, 6(1), 60-66. doi:10.1037/0882-7974.6.1.60

Siu, K.-C., Chou, L.-S., Mayr, U., van Donkelaar, P., \& Woollacott, M. H. (2008). Does inability to allocate attention contribute to balance constraints during gait in older adults? The journals of gerontology. Series A, Biological sciences and medical sciences, 63(12), 1364-1369.

Stinchcombe, A., \& Gagnon, S. (2013). Aging and driving in a complex world: Exploring age differences in attentional demand while driving. Transportation Research Part F: Traffic Psychology and Behaviour, 17, 125-133. doi:10.1016/j.trf.2012.11.002

Strayer, D. L., Drews, F. A., \& Johnston, W. A. (2003). Cell phone-induced failures of visual attention during simulated driving. Journal of Experimental Psychology: Applied, 9(1), 23-32. doi:10.1037/1076-898X.9.1.23

Tarnanas, I., Schlee, W., Tsolaki, M., Müri, R., Mosimann, U., \& Nef, T. (2013). Ecological validity of virtual reality daily living activities screening for early dementia: longitudinal study. JMIR serious games, 1(1). doi:10.2196/games.2778

Törnros, J., \& Bolling, A. (2006). Mobile phone use - effects of conversation on mental workload and driving speed in rural and urban environments. Transportation Research Part F: Traffic Psychology and Behaviour, 9(4), 298-306. doi:10.1016/j.trf.2006.01.008

Trick, L. M., Toxopeus, R., \& Wilson, D. (2010). The effects of performance in older adults. Accident Analysis \& Prevention, 42(6), 1661-1671. doi:10.1016/j.aap.2010.04.005

Verhaeghen, P., \& Salthouse, T. A. (1997). Meta-analyses of age-cognition relations in adulthood: Estimates of linear and nonlinear age effects and structural models. Psychological Bulletin, 122(3), 231-249. doi:10.1037/0033-2909.122.3.231

Yang, Y., Bender, A. R., \& Raz, N. (2015). Age related differences in reaction time components and diffusion properties of normal-appearing white matter in healthy adults. Neuropsychologia, 66, 246258. doi:10.1016/j.neuropsychologia.2014.11.020

Zelditch, M. (2007). The external validity of experiments that test theories. In M. Webster \& J. Sell (Eds.), Laboratory experiments in the social sciences (pp. 87-112). Amsterdam, Boston: Academic Press. 